\title{
Regulatory Compliance Management in the Professional Sport Industry: Evidence from the Italian Serie A
}

\author{
Eugenio D’Angelo ${ }^{1}$ \\ ${ }^{1}$ Department of Economics and Legal Studies, Pegaso Telematic University, Naples, Italy \\ Correspondence: Eugenio D’Angelo, Department of Economics and Legal Studies, Pegaso Telematic University, \\ Naples, Italy.
}

Received: February 2, 2018

Accepted: February 7, 2018

Online Published: February 19, 2018

doi:10.5539/ibr.v11n3p149

URL: https://doi.org/10.5539/ibr.v11n3p149

\begin{abstract}
The football industry has grown consistently in the last three decades and now is capable to generate revenues for approximately 18.5 billions euros per year. Despite this growth, football teams failed to translate this opportunity into profits and financial sustainability, thus incurring in substantial losses. For this reason the Union of European Football Associations (UEFA) has issued a regulation to induce a change this behavior, reducing debt, decreasing employees costs and reaching the break event point. However, if we use the regulatory compliance management theory to analyse and predict the extent to which sports teams will comply with UEFA's financial regulations, we find that there are several reasons to believe that such compliance will not be achieved. Gathering data from Aida - Bureau van Dijk - we have investigated Italian teams compliance, comparing the economic results achieved before and after the introduction of the Financial Fair Play regulation in a nine-year period of observation. Result show that there are no significant differences in firms' performance, thus our hypothesis has been confirmed. Furthermore, we have investigated if any remarkable change has been produced in terms of competition in the Italian major football league. Consistently with our hypothesis, results confirm that an unwilling process of concentration, in terms of on the field results, is taking place.
\end{abstract}

Keywords: regulatory compliance management, UEFA financial fair play, Italian serie A

\section{Introduction}

According to the Club Licensing Benchmarking Report for the financial year 2016, the European football club revenues are now six and a half times what they were in 1996 (Club Licensing Benchmarking Report, 2016). In 2016, revenues raised to 18,5 billions euro, with a yearly increase of $9,5 \%$, following a $6 \%$ increase over the previous year. These revenues are mainly depending on domestic broadcast (34\%), sponsorships (24\%), gate receipts $(15 \%)$, International broadcasting $(10 \%)$ and commercial $(9 \%)$, besides other residual sources of revenues. Of course the importance of this industry for its stakeholders has risen with its revenues. If in the ' $80 \mathrm{~s}$ the football industry was mainly a concern for supporters, now it has become a significant business for investors, media and sponsors (Kennedy, 2013, Storm and Nielsen, 2012). However, even if this seems to be an exciting growth story, which in other industries may have been likely to generate wealth and profits, the football industry didn't work this way. If we look at clubs financial statements, we can easily state that clubs failed to convert this opportunity into profits (Dimitropulos, Leventis and Dedoulis, 2016).

This circumstance has not been underestimated by the highest European football organization, the UEFA (Union of European Football Associations) that, in 2010, approved the so called "financial fair play regulation" (FFPR) that came into full force in 2013. The purposes of this regulation are to improve the economic and financial capability of the clubs, increasing their transparency and credibility, to place the necessary importance on the protection of creditors and to ensure that clubs settle their liabilities with players, social/tax authorities and other clubs punctually, to introduce more discipline and rationality in club football finances, to encourage clubs to operate on the basis of their own revenues, to encourage responsible spending for the long-term benefit of football and to protect the long-term viability and sustainability of European football clubs (Uefa Club Licensing and Financial Fair Play Regulation, 2012 and 2015).

In order to accomplish these objectives, UEFA has introduced some regulation guidelines, besides other provisions, that specify the clubs' expected behavior, mainly, in terms of costs, profits, debt and investments. In terms of costs, the regulation states that the employees' benefits cannot exceed the $70 \%$ of revenues. In terms of 
profits, the UEFA has introduced the so-called "break-even requirement" (B.E.R). According to this provision, relevant revenues should not be exceeded by relevant costs. Briefly, relevant income and relevant costs are the ones related to the core business of the club, excluding income taxation. However the regulation allows clubs to have an acceptable deviation from the "relevant" zero-profit condition. This acceptable deviation has been defined equal to 5 millions euro for each monitoring period, that consists of three financial reporting years ( $\mathrm{T}$; T-1 and T-2). Moreover, this threshold can be branched and raised to 45 millions for the license seasons 2013-14 and 2014-15 and to 30 millions for the license seasons 2015/16, 2016/17 and 2017/18, if this deviations is entirely covered by equity contributions. In terms of debt, the regulation states that the net debt doesn't have to exceed the $100 \%$ of total revenues. Finally the regulation is deeply focused on improving investment in infrastructures, including the stadium and the training facilities, whose costs are excluded from the relevant expenses to calculate the B.E.R. in a given monitoring period.

If a club fails to comply with the regulation, the UEFA's Club Financial Control Body will decide the appropriate sanction which can lead, in some cases, to the disqualification from the in progress international competition or from future international competitions.

Given the importance of international competitions, not only in terms of direct revenues, but also in terms of commercial opportunities, in its wider definition, it apparently seems unavoidable the necessity to comply with the described regulation. However, if we deeply analyse the peculiarities of this industry in terms of ownership and control, in terms of objectives, which are not always in line with profit orientation, and in terms of the stakeholders' power, we can recognize that the pressure to comply considerably decreases. Moreover the pressure to comply is directly linked not only to firms' characteristics, but also to the regulations ones and to the way this to elements relate to each other. Therefore we recognize a possible way to deal with the FFPR that is the application of the so-called theory of regulatory compliance management.

As we will theoretically demonstrate in the next section of the paper, there are reasons to believe that compliance to the UEFA regulation will be not achieved. Moreover in the last section of the paper we will investigate the degree of compliance through an empirical analysis conducted on the Italian Serie A.

Besides the introduction, the paper falls in to four sections. In the first section we will focus on the literature review concerning the FFPR and the compliance management theory and we will formulate the hypothesis. The second section will be dedicated to the methodology. In the third section we will display the empirical results of the study. In the last section we will sum up the contribution of the paper, its limitations and suggest further streams of research.

\section{Literature Review and Research Hypotheses}

Even if the sport industry, as explained in the previous section, has grown consistently in the last three decades, there is still an important issue to deal with, which is the coexistence of two objectives, namely, the success on the field and the success in the financial statement. But is this really something that we may concern? Is it really an issue? European football clubs, as pointed out, among others, by Dimitropulos (2011) and Ogbonna and Harris (2014), still have a management culture which consider the emotional logic of winning on the field as a priority compared to the financial and economic result. This is mainly due to the concentration of equity stakes, which leads to the almost absent separation between ownership and control. Even when a professional manager, different from the majority owner, is in charge, the owner has a substantial interference in strategic choices and this implies that the management ends up being in charge on paper only. Owners are often wealthy individuals (Kennedy, 2013) who are interested in sport to fulfil different needs, other than direct profit maximization, such as higher prestige or power. For example, as stated by Iaria (2012) speaking about Silvio Berlusconi, "It's almost impossible to untwine football from his political and business dealings". Moreover, besides non-economic (Maslow, 1954) but still rational objectives, there are furthermore economic motivations that can lead to overinvestment and losses in sport businesses. What we, prima facie, can recognize as benefactors owners or "sugar daddies", besides direct beneficial results in terms of legitimacy or higher public citizenship, in reality, can also have positive results in other business connected to the sport one, in terms, for example, of cost of capital. Moreover, the winning orientation instead of profit orientation can also be explained through the stakeholder theory.

Besides the owner personal orientation there is a substantial contribution to this behavior, which is given by a primary stakeholder as supporters. Supporters, for a sport firm, are something different and definitely more important and pre-eminent in the life of the company than common customers are for a company operating in another industry. When a club obtains poor results on the field, supporters are used to demand for new and costly players and they don't care about the financial sustainability of these transactions (Solberg and Haugen, 2010). 
Someone may say that club can simply ignore this request, but this choice is not so simple, given the negative effect it can have on the stadium attendance, to the revenues from the media, from the merchandizing and so on. In addition, is not even rare that supporters react with animated and violent protests. For these reasons, the owner of a professional football club may neglect the importance of financial sustainability and focus more directly on the on field results (Michie and Oughton, 2005).

Therefore, a wide body of previous research demonstrate that football clubs behave as win oriented instead as profit oriented (Kesenne, 1996; Vopel, 211; Storm, 2012) and this could be seen even through the methodical overinvestment which has characterized professional clubs in recent years. Clubs are used to obtain poor financial results and to fill this gap through substantial equity contributions. This circumstance has led the previous literature to define the sport industry as a "rat race" or as a "zombie race". As pointed out by Budzinski (2014), this leads to the methodical market failure (Muller et al., 2012) because, in this industry, firms compete for a fixed and indivisible reward (that is the first place in a competition), since only the winner (the fastest rat) gets the compensation (the cheese). In other terms, is clear that all competitors are used to increase their equity contribution without increasing their expected output (which is fixed). This will result in a lack of efficiency (Akerlof 1976). The concept of zombie race (Frank, 2014) is even more appropriate for this industry, given that a substantial part of the competing clubs is technically bankrupt, but continue to act like this wasn't their condition.

Given these characteristics of the industry and of its players, we now attempt to join it to the literature in terms of managerial compliance to regulation. This stream of research investigates the problem of ensuring that an enterprise is structured and behave in a way that is recognize to be in accordance to a given regulation and its guidelines.

Regulatory Compliance Management deals with modelling, checking, enforcement and analysis of compliance requirements extracted from regulations of diverse kind such as laws, contract, internal policies, etc (El Kharbili, 2012). Regulation guidelines, to which firms should comply, specifies the expected behavior and defines tolerated and non-tolerated deviation from the defined archetype and the sanction in which a given subject may incur if not complying. Recent research in the field has stated that when a firm has to comply with a given regulation, one or more department of the firm, such as finance, administrative, information system, etc., may be somehow involved in a change which mostly implies an investment (Perskow, 2003). Research trends in the field of regulatory compliance mostly focus on different types of domains (healthcare, finance, etc.), types of regulatory compliance (policy, contract or regulations) and solutions, typically detective type or preventive ones. However there are some studies that have addressed the issue of motivation to comply or not to a given regulation. In a study conducted by Amodu (2008) is shown a very clear literature review concerning determinants of compliance and business motivation to comply. In summary, as stated by Kagan (1994), there are a number of variables influencing the enforcement activity: legal design factors, such as stringency of regulatory mission, legal power and specificity of legal standards and penalties, task environment factors, such as visibility of violations, regulated entities' willingness to comply or seriousness of risks to be prevented, political environment factors, such as strength and aggressiveness of pro-regulation interests or preferences of political authorities (influenced by recent catastrophes, economically urgent projects subject to regulation, etc.) and leadership factors, such as reactive or strong-minded regulatory leaders and degree of staff professionalism. Among other motivation in the decision to comply or not to comply, there are some that are definitely useful to predict the orientation in the field of the sport industry.

Kagan and Scholz (1984) state that compliance is more likely when firms are able to pass on the costs of compliance. For example when these costs can be transferred to a third party like costumers. Of course this is not the case of the FFPR, since, contrariwise, compliance will result in firms financial constraint that will imply them to be less likely to hire talented player and thus generate supporters disappointment and reduce their willingness to pay more for tickets and for media subscriptions.

The perceived effect on reputation is another aspect that may influence the decision to comply. According to the previous literature, it can be simplistic to assume that firms make calculation in order to decide whether to comply or not on the basis of their profit maximization. Fisse and Braithwaite (1993), inquiring this aspect, found that firms are more likely to comply when they think that their reputation will be otherwise affected in a negative way. The same importance given to reputational factors was stated in other works, which highlighted that this concern is even higher in larger firms (Gunningham, 2005). This condition, as well as the previous, unquestionably cannot be found in professional teams when it comes to comply with the FFPR. First of all because their primary concern, in terms of reputation, is related to the reputation perceived by their supporters and, secondly, because, unless they are disqualified from an international competition, their reputation will not 
be affected. And we know that the disqualification of a team from the UEFA Champions League or Europe League is definitely a remote event.

Another reason that may influence the decision to comply is closely related to the reputational one and it regards the sanctions or penalty linked to the decision to not comply. Parker (2002) defined the concept of "fear factor" when addressing this issue. The fear to be sanctioned can be a powerful trigger to comply. Is clear that also in this case, teams are not that much motivated to comply since in the last 15 years we have seen only 53 cases of disqualification from the UEFA competitions, which is a relatively small number if we consider that every year about 150 teams take part in the UEFA competitions.

Co-operation and trust are other element to take in account. In this perspective, as stated by Kangan and Scholtz (1984) and by Black (1976), firms are more likely to comply when they agree with the regulation and when there is proximity ("relational distance") with the regulatory body. Falling this concept in our industry, we can say that is not rare to see teams contesting the UEFA decisions, particularly when it comes to the FFPR. In summer 2017, for example, some teams questioned the capability of Paris Saint Germaine to fulfil the FFPR requirements after hiring Nejmar Jr. from Barcelona for over 200 millions euro. However, at the moment this player is currently taking part to the national and international competitions, without any concomitant verification by the UEFA.

The economic climate may have also an influence on the decision to comply (Atlas, 2007). In other words, the more economically difficult is the environment, the more permissive will be the reaction to a limited compliance. Also in this case, given the substantial losses experienced by European teams, we will predict a temporary tolerance in terms of sanctions and, therefore, a lower compliance at least in the short term.

Another very important element in the compliance management theory is the convergence of interests between the public and private interest. According to this principle, compliance will be more likely when there is a convergence of interest. In our case we can see a convergence of interest but it seems to be the other way round. In other words, both teams and the UEFA, for different reasons, my probably converge over a lower compliance rather than strict compliance to maximize their utility function in the short term.

Moreover, according to literature, firm size and third party stakeholders are likely to influence the willingness and the capability to comply. Small businesses encounter more difficulties to comply than their larger counterparts. In addition, media, costumers (supporters) and social forces can shape the compliance attitude al well (Hutter and Jones, 2006). In this industry we are typically dealing with large firms and with high stakeholders pressure to not comply.

According to Genn (1993) other factors, which encourage compliance, are the ownership dispersion and the workforce resistance or pressure. In our case, ownership and workforce orientation are both resistant to compliance. The way in which ownership are motivated to compliance have been previously discussed and, of course, motivations affecting the workforce are evident, since the first provision of the FFPR requires a reducing their salaries.

Therefore, all these reasons concerning the regulatory compliance management lead us to formulate our hypothesis in the following way: "Professional football teams are not complying with the main regulatory requirements contained in the UEFA Financial Fair Play Regulation”.

\section{Materials and Method}

In order to determine the sample on which focus our analyses, we first proceeded to analyse the ranking of the Italian Serie A in the last 10 years. The Serie A championship is composed of 20 teams each year, but clearly, over the last 10 years, more than 20 teams have taken part to this competition. In particular, the teams that have competed in the Italian Series A, in the last ten years, were 33. In order to assess the greater or lesser compliance with the FFPR, it was decided to limit the analysis to those teams that have played most of the times in the major Italian competition and who have achieved the best results on the field. For this reason, to each team and in each season was given a score ranging from 1 to 20, depending on the position achieved in each season. In other words, a score of 20 points has been given to the team that won the championship and only one point has been given to the one that arrived last. The result of this allocation made it possible to order the teams according to the results achieved in ten years of competition. Subsequently, all the teams that no longer compete in Serie A, or who have not achieved significant sporting results in the last 10 years, have been removed from the sample. The sample was therefore limited to the 15 teams of major importance, as shown in the following table (Table 1). 
Table 1. Sample definition

\begin{tabular}{|c|c|c|c|c|c|c|c|c|}
\hline \multicolumn{6}{|c|}{ All Italian Teams } & \multicolumn{3}{|c|}{ Selected Sample } \\
\hline Ranking & Team & Score & Ranking & Team & Score & Ranking & Team & Score \\
\hline 1 & Juventus & 185 & 18 & Bologna & 48 & 1 & Juventus & 185 \\
\hline 2 & Roma & 172 & 19 & Sassuolo & 37 & 2 & Roma & 172 \\
\hline 3 & Inter & 166 & 20 & Siena & 26 & 3 & Inter & 166 \\
\hline 4 & Milan & 162 & 21 & Empoli & 23 & 4 & Milan & 162 \\
\hline 5 & Napoli & 161 & 22 & Verona & 20 & 5 & Napoli & 161 \\
\hline 6 & Fiorentina & 144 & 23 & Bari & 12 & 6 & Fiorentina & 144 \\
\hline 7 & Lazio & 135 & 24 & Cesena & 9 & 7 & Lazio & 135 \\
\hline 8 & Udinese & 110 & 25 & Lecce & 8 & 8 & Udinese & 110 \\
\hline 9 & Genoa & 95 & 26 & Reggina & 7 & 9 & Genoa & 95 \\
\hline 10 & Sampdoria & 90 & 27 & Crotone & 4 & 10 & Sampdoria & 90 \\
\hline 11 & Atalanta & 79 & 28 & Carpi & 3 & 11 & Atalanta & 79 \\
\hline 12 & Palermo & 77 & 29 & Livorno & 3 & 12 & Chievo & 73 \\
\hline 13 & Chievo & 73 & 30 & Brescia & 2 & 13 & Cagliari & 66 \\
\hline 14 & Cagliari & 66 & 31 & Frosinone & 2 & 14 & Torino & 61 \\
\hline 15 & Parma & 64 & 32 & Novara & 2 & 15 & Bologna & 48 \\
\hline 16 & Torino & 61 & 33 & Pescara & 2 & & & \\
\hline
\end{tabular}

For all the 15 teams belonging to the final sample, we gathered ten years financial statements (profit and loss and balance sheets) from the AIDA (Borough Van Dijk) database. For some of the teams, Milan, Inter, Bologna and Juventus, data were available for 2017 but not for 2007, while, for all the others, data were available from 2007 to 2016. Therefore to ensure the homogeneity to the analysis, we decided to investigate only the period between 2008 and 2016 that was available for the whole sample.

Since the objective of the study was to verify to which extent the management of the series A teams adjusted their business to the provisions of the FFPR, it was necessary to focus on the variables that the regulation examines for evaluate teams compliance. Generally speaking, the FFPR, since its very first version, specified its main concerns, which can be grouped into 4 main aspects:

1. Reduction of personnel costs

2. Self-financing

3. More rational economic management

4. Investments in training facilities and stadiums

5. Debt reduction

Therefore, for each of the aforementioned aspects, we defined appropriate variables to measure the achievement of the objective, through comparing the performances achieved in the period before and after the introduction of the new regulation.

The variables used in the study were the following:

1. Employee costs / Revenues = this variable is representative of the impact of personnel costs on sales. It is quite clear that, with the introduction of the regulation, the UEFA would expect a reduction of this index.

2.1 Break Even Result = this variable is the sum of the pre-tax income for the last three years which, as mentioned, should not generate a loss of more than 5 millions euro, or 30-45 millions respectively in the first two years after the introduction of the regulation and thereafter, only if this acceptable deviation is fully offset by an increases in capital. The UEFA would expect the compliance of this requirement.

2.2 Equity contribution = this variable is the expression of the self-financing capacity of the clubs. UEFA would expect a lower capital increases in the period following the introduction of the new regulation.

3.1 Roa = Operating Income $/$ Total Asset $=$ this variable is representative of the profitability of the assets. UEFA would expect this index to increase with the introduction of regulation.

3.2 Ros = Operating Income / Revenues = this variable is representative of the profitability of sales. UEFA would expect this index to increase with the introduction of regulation.

3.3 Standard Deviation in \% Change of operating income = this variable, as have been used in previous studies (Titman and Wellels, 2014) was taken into account as a proxy of volatility. It would have been desirable for UEFA that clubs have reduced the volatility of their income after the introduction of the regulation.

3.4 Other operating costs / Revenue $=$ this variable is representative of the incidence of other operating costs on club revenues. UEFA would expect a reduction of this variable. 
4. Tangible Assets $/$ Total Assets = this variable was used to measure investments in infrastructure that have been made by clubs. An increase in this index in recent years would have been desirable by the UEFA.

5.1 Debt / Revenues = this variable is representative of the company's indebtedness in relation to the size of revenues. A reduction of this variable, since the introduction of the regulation, would have been necessary according to the UEFA prescription.

5.2 Equity / Total Assets = this index expresses the capitalization of the company and therefore its capital structure. In the intent of the regulation, this index should have increased and, more particularly, it should have increased due to self-financing rather than as a result of equity contribution.

After verifying, through a descriptive statistics, the trend of the aforementioned variables, we will proceed to verify the statistical significance of the difference in the results achieved, through a T-test on the average values reported in the period before and after the introduction of the new regulation. In addition, given that the reduction in dependence on external sources of capital had the intent to reduce the financial patronage that had influenced the results of the years preceding the introduction of the regulation, the Gini concentration index, calculated on the points scored by the Serie A teams, was analysed to check whether, in the period following the introduction of the regulation, there have been greater or lesser competitive parity. Data have been analysed with SPSS.17.

\section{Results and Discussion}

In this section of the work we will first examine the descriptive statistics for the variables described in the previous section for the clubs included in the sample for the period 2008-2016. Subsequently we will report the results of the T-tests comparing performances in the period before and after the introduction of the regulation and, in the end, we will show the result of the comparison relative to the Gini concentration index in the period under analysis.

UEFA's first element of concern, in the development of regulatory discipline, was to limit inflation. It is well known that the income statement and the structure of the club business largely depends on personnel costs, since the remuneration of the athletes has always been considered the primary source of competitive advantage for the teams, thus they are used to largely invest in this assets.

As can be seen from the next graph (Figure 1), which shows the average of the ratio between personnel costs and sales in the period under investigation, there has been a clear reduction of this incidence since 2012. The index has changed from an average value of $65 \%$ in 2011 to $58 \%$ in 2016. Note that the provisions of the financial fair play would require this index to be less than $70 \%$. Therefore, on average, the clubs seem to have contracted considerably the most important cost item of their budgets. Although in the last three years the trend seems to be increasing again. In 2016 the only clubs that reported a value superior to 70\% were Lazio, Milan and Bologna, while in 2011 there were 7 clubs exceeding this threshold. However, the average mean of the sample didn't exceed the $70 \%$ limit in the overall period of investigation.

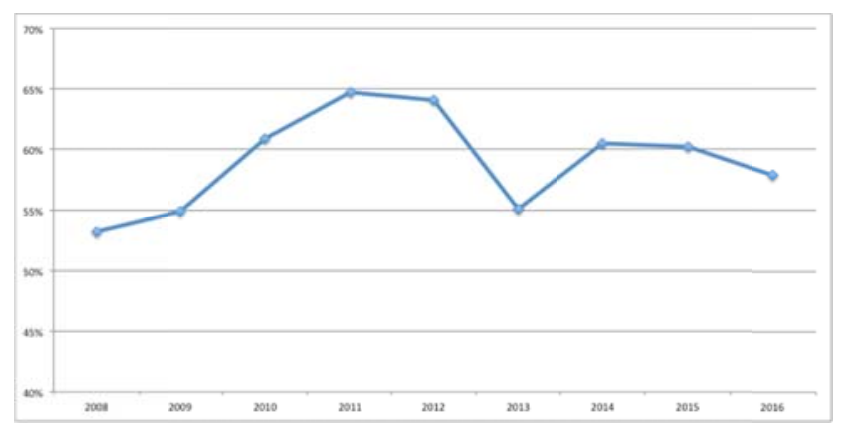

Figure 1. Employee Costs/Sales ratio

The following graph (Figure 2) shows the performance of the Break Even Result, the sum of the pre-tax results achieved by the clubs in the three years preceding the monitoring period (T, T-1 and T-2). It can be noted that the performance of this index shows a noticeable improvement from the 2013-2014 monitoring period compared to the previous periods. The losses of the 15 teams have settled on a value close to 600 million euros per year in last three monitoring periods, an average of about 44 million euros per team. This is a result close to what is required by the new regulation and significantly improved with respect to the monitoring period 2012 and 2013. More in detail, the teams that in 2016 showed a value lower to a loss of 5 million euro requested by UEFA were 7, while 8 clubs lost less than 30 million (Rome, Genoa, Fiorentina, Inter, Bologna and Milan have instead lost more than 
45 million in three years). The worst result achieved in terms of Break Even Analysis was found in 2011 and 2014 where only 4 teams were adequate to the mentioned parameters. From the analysis carried out it emerged that only Napoli and Cagliari have never achieved a three years cumulated loss superior than 5 million euros and that only Lazio, Chievo and Atalanta have respected for all the years of analysis at least the acceptable deviation of 45 million euros of losses in the three years.

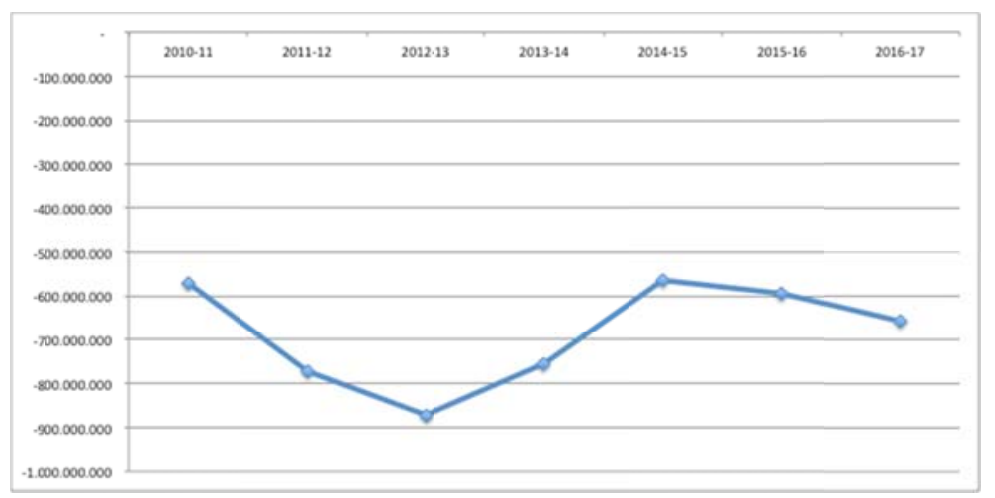

Figure 2. Aggregate Break Even Result

The intent of the regulation was, among others, to reduce the owners' contributions. For this reason it was considered appropriate to investigate the trend of capital increase, not due to self-financing, of teams in the last ten years. The analysis shows that, excluding the years 2012 and 2013, when the maximum at the minimum of the equity contribution was respectively found, the trend was crescent in the last three years compared to the previous three-year period 2008-2010 (Figure 3). Lazio, Udinese, Cagliari and Napoli are the only teams that have never provided capital contributions during the observation period. Inter and Milan, on the other hand, are those that have achieved the greatest increase in equity through external sources (about 1,1 billions euros in ten years).

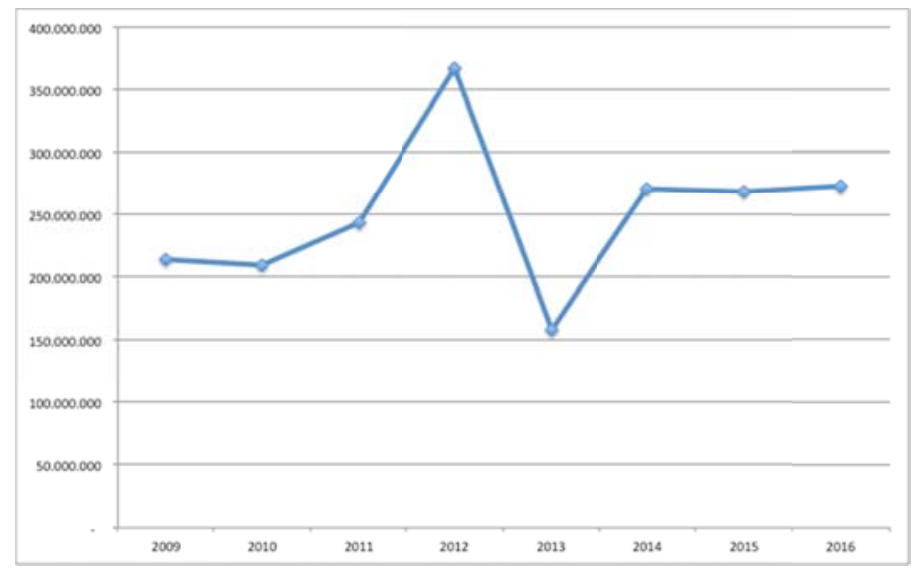

Figure 3. Equity contribution

The following graph (Figure 4) shows the trend in profitability. The trend, although with very different oscillations, appears to be cyclical in the ten years of the survey. Since the entry into force of the new regulations, there has been a decline in profitability, which has only recovered in the last year of analysis. Also for these indicators, Napoli, Lazio, Chievo and Cagliari achieved the best performances. 


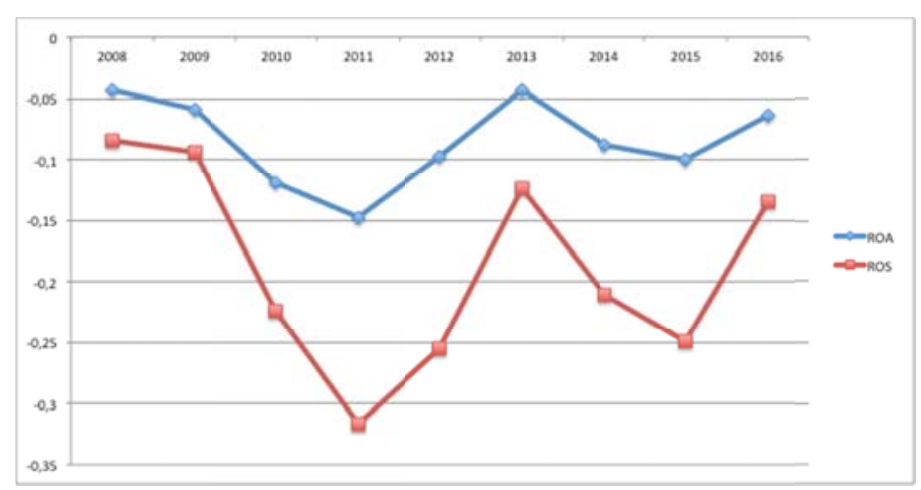

Figure 4. Return on Asset and on Sales

Volatility, that we measured with the standard deviation of the percentage change in operating income, after the peak reached in 2014, has settled on more moderate values in the last two years and close to those recorded in 2012 and 2013 (Figure 5).

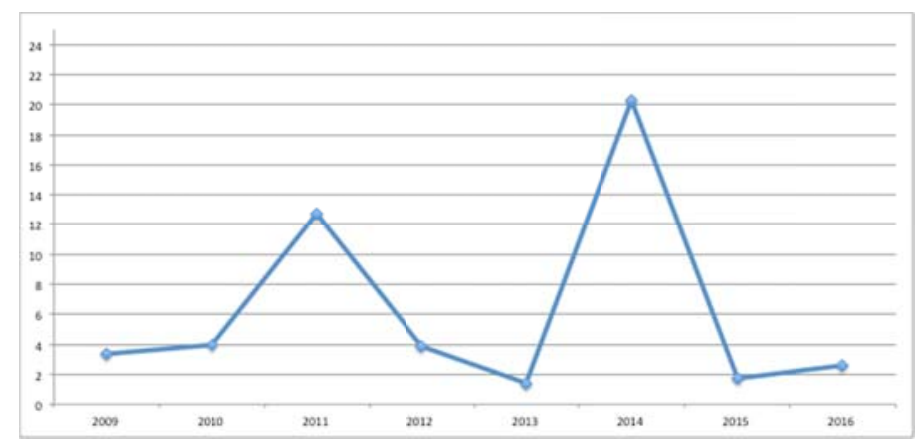

Figure 5. Standard deviation of the \% change in operating income

Also with reference to the performance concerning the other operating costs, it is noted that firms performed a decreased in 2013 and then the value increased again in the following years. Year 2016 also represents a return to more acceptable values for this variable (Figure 6).

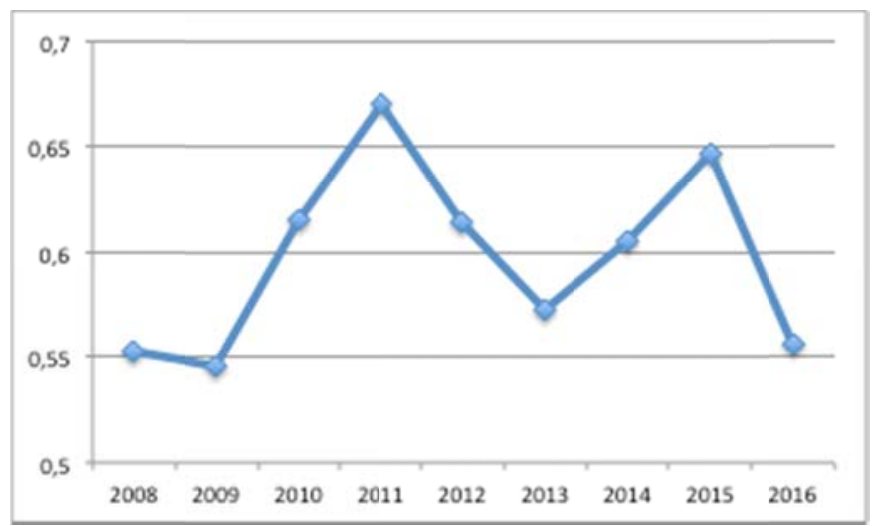

Figure 6. Other operating costs/Sales

With reference to the investments in tangible assets, it has been noted that, compared to the three-year period 2008-09, the company has settled on higher values. However, in an absolute sense, the index continues to present a totally marginal value compared to intangible assets, among which are typically accounted for the multi-year rights on the athletes' sporting performance, as well as on the value level. The ratio between tangible assets and total assets is on average 6\% and has not substantially increased in recent years. Excluding Juventus (28\%), Lazio (17\%) and Cagliari (16\%), the average of the other teams fell to 2.1\% (Figure 7). 


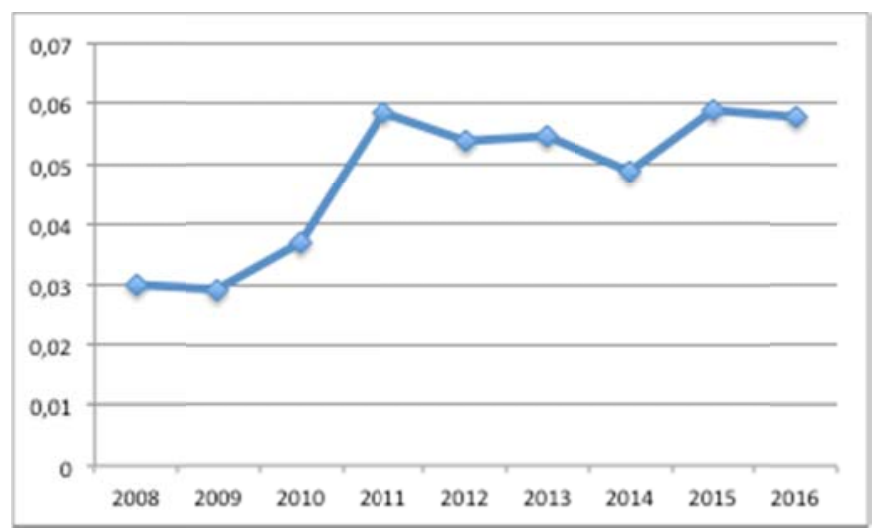

Figure 7. Tangible Assets / Total Assets

From the point of view of debt sustainability and capital structure, we have analysed the ratio between debts and total revenues and the ratio between equity and total liabilities. With reference to the first index, the trend is clearly decreasing in the period following the introduction of the regulation. Clubs are, slowly but constantly, reducing debt in relation to revenues. This circumstance makes it possible to state that a certain positive effect of the regulation has occurred. However, substantially different performances remain within the sample. If clubs such as Fiorentina, Napoli, Torino, Atalanta and Sampdoria have achieved a value lower than $100 \%$, there are clubs that continue to have a ratio between debts and revenues of higher than $200 \%$, is the case of Udinese, Lazio and Milan (Figure 8).

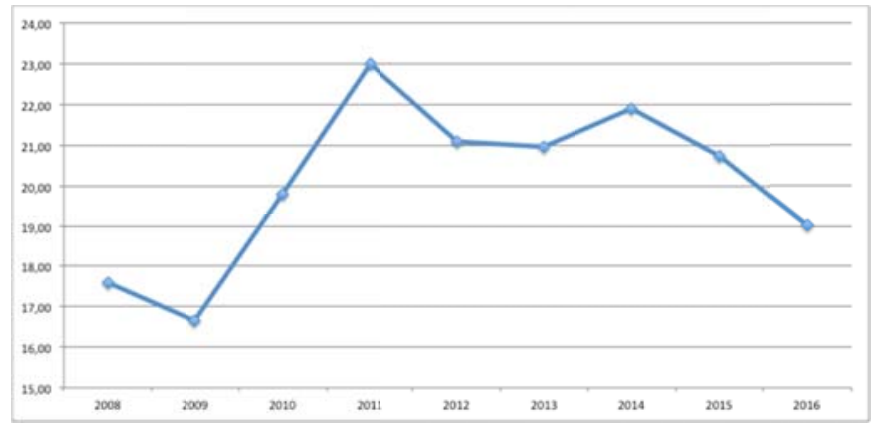

Figure 8. Debt / Revenues

As already mentioned, the regulation reduced the possibility of overcoming operating losses through indiscriminate equity increases, placing an acceptable deviation of 45 million for the first two years of application and 30 million for the subsequent monitoring period. The combined effect of the reduction in capital increases and the demand to reduce payables and personnel costs should have led companies to an increase self-financing. The trend of the ratio between equity and total assets is however clearly falling in the observation period and now averaging around $16 \%$. Moreover, some differences within the sample appear to be evident. If Fiorentina, Naples, Lazio, Inter, Cagliari and Torino have shown an equity ratio superior to $30 \%$, some companies such as Rome, Milan, Genoa and Chievo prove to be heavily under-capitalized. For Rome, Milan and Genoa the index is even close to $1 \%$ (Figure 9).

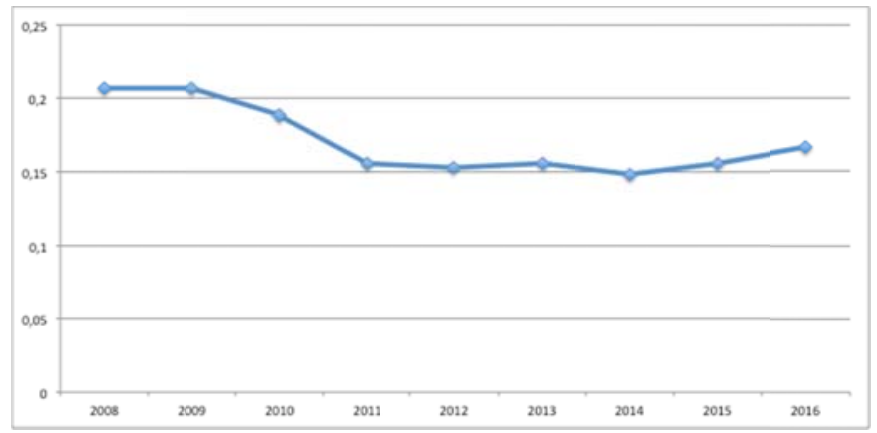

Figure 9. Equity / Total Assets 
The trend of the average values shown in the graphs does not clarify whether companies' performances has been shown to differ significantly in the two periods of investigation (the previous and the one after the introduction of the regulation). Table 1 shows the results of the T-test through which we compared performances means reported in the previous and following period.

Table 1. Mean difference T-test

\begin{tabular}{|c|c|c|c|c|c|c|c|c|c|}
\hline Variables & $\mathbf{N}$ & Ante & Post & Mean Difference & Corr & Sig. & T-Test & df & Sig (2-tailed) \\
\hline B.E.R. & 45 & -49.266 .157 & -40.455 .000 & -8.811 .157 & 0,66 & 0,00 & $-0,85$ & 44 & 0,40 \\
\hline Debt / Sales & 60 & $128,39 \%$ & $137,69 \%$ & $-9,30 \%$ & 0,60 & 0,00 & $-1,43$ & 59 & 0,16 \\
\hline R.O.S. & 60 & $-18,04 \%$ & $-17,98 \%$ & $-0,06 \%$ & 0,25 & 0,05 & $-0,01$ & 59 & 0,99 \\
\hline R.O.A. & 60 & $-9,24 \%$ & $-7,35 \%$ & $-1,89 \%$ & 0,19 & 0,15 & $-0,79$ & 59 & 0.43 \\
\hline Equity / Total Assets & 60 & $18,98 \%$ & $15,69 \%$ & $3.29 \%$ & 0,55 & 0,00 & 1,77 & 59 & 0,08 \\
\hline Tangible / Total Assets & 60 & $3,86 \%$ & $5,50 \%$ & $-1,64 \%$ & 0,80 & 0,00 & $-2,37$ & 59 & 0,02 \\
\hline Employee Costs / Sales & 60 & $58,42 \%$ & $58,42 \%$ & $0,00 \%$ & 0,33 & 0,01 & 0,00 & 59 & 1,00 \\
\hline Other Operating Costs / Sales & 60 & $59,61 \%$ & $59,56 \%$ & $0.05 \%$ & 0,31 & 0,01 & 0,02 & 59 & 0,98 \\
\hline Std. Dev. of \% Change in Operating Income & 60 & $-155,87 \%$ & $-159,41 \%$ & $3,53 \%$ & 0,05 & 0,69 & 0,02 & 59 & 0,98 \\
\hline Equity Contribution & 60 & 15.791 .667 & 14.938 .333 & 853.333 & 0,68 & 0,00 & 0,26 & 59 & 0,80 \\
\hline
\end{tabular}

Results show that there has been an improvement in B.E.R., which led to lower losses of around 8 million euros. The same can be said with reference to the reduction in payables debt to revenues (-9.3\%). Operational profitability, measured by ROS and ROA, was slightly lower, respectively $-0.06 \%$ for ROS and $-1.89 \%$ for ROA. On the other hand, capitalization increased by 3.29 percentage points. The average equity contribution decreased for about 850.000 euros and volatility also increased. No significant differences were found in the incidence of the salaries and other operating costs on revenues. The ratio between tangible assets and total assets was even slightly decreased. None of the differences between the variables observed in the preceding and following periods is 99\% significant at the T-test. The only one that can be evaluated in this sense is the ratio between tangible assets and total assets that is negative, in clear contrast with the requirements of the regulation.

The reduction of the equity contributions by the owners should have had the effect of guaranteeing greater competitive equality between teams, limiting the ability of the equity holders to make up for their finances with the operational losses resulting from the attempts to achieve better sports results. In order to evaluate this aspect, the Lorenz curves were constructed for the various years object of observation. As the distance of the Lorenz curve from the line of competitive equality increases, a higher competitive disparity would emerge, vice versa a reduction of the area between the Lorenz curve and the oner of competitive parity would be found in the case of greater competitive parity. It is evident that the curves are not substantially different in the two survey periods. The curves that have been traced from 2012-13 to 2015-16 are very similar to the previous ones; indeed there is a slight increase in competitive disparity (Figure 10).

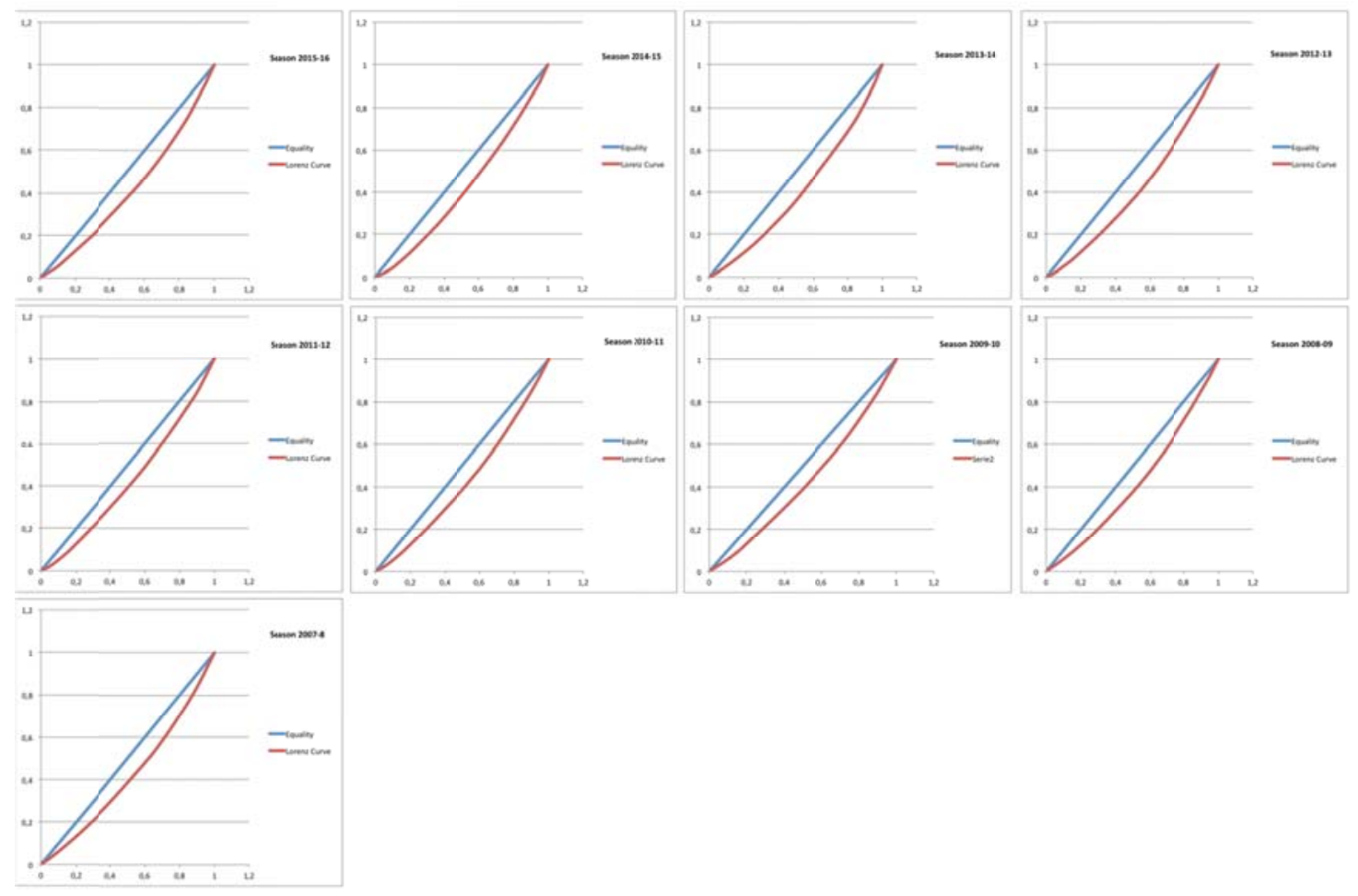

Figure 10. Lorenz Curve 
Moreover, dividing by 0.5 the value of the area below the Lorenz curve, we have reached the Gini concentration index. This index summarizes the level of competitive parity in the championship. As the Gini index grows, we would be in a position of lesser competitive equality, while, in case of a decrease, we would find a condition of greater competitive equality.

The following graph shows the trend of the index in the observation period. In fact, what is seen graphically with the Lorenz curves is confirmed. The competition in the Serie A championship, from 2013 onwards, shows a clear countertrend compared to the previous period. The competitive parity is in fact significantly worse (Figure 11).

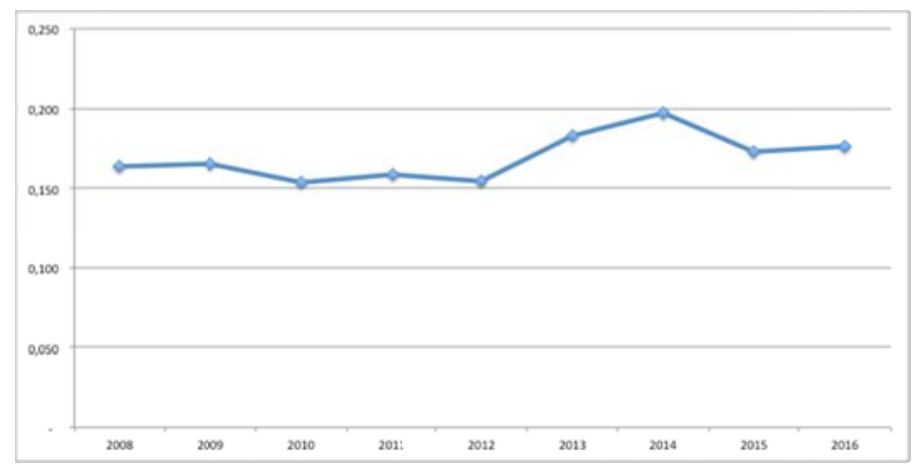

Figure 11. Gini index

\section{Conclusion}

Fair play is undoubtedly a crucial value in every sport. This term, in its usual meaning, implies a way of competing that is non-discriminatory and therefore based on the concept of equivalent opportunity (Lenk and Gunter, 1989). In other words each participant should be treated in the same way and, in the long run, should have the same opportunity to succeed in a given competition. When it comes to the FFPR, we should then assume that all teams should be treated in the same way and that, in the long run, each clubs can reach the same economic result, which may lead to an analogue chance to win on the field. This not only cannot be reached because of some substantial characteristics of the industry, but also is even very difficult to be achieved because of the unwillingness of the main stakeholders. The paper has demonstrate through a descriptive ant T-test statistic that the compliance to the UEFA's regulation is far to be accomplished at least by Italian teams. The explanation given by this article to the unsuccessful compliance has been found in the field of regulatory compliance management, providing theoretical motivation that definitely seems to be realistic and plausible. It is clear that the paper can be taken as a starting point to future research in several ways. First of all we can focus on the teams that have more probabilities to enter the UEFA's competition, instead to all teams, to see if there are substantial differences in results. Someone may say that teams that are more likely to participate to international competition can be seen as a more appropriate sample to test the hypotheses, we do not believe this way since in the last two seasons teams such as Atalanta or Sassuolo qualified for the Europe League competition. Furthermore we can extend the study to other countries in order to address the same problem in other leagues.

\section{References}

Akerlof, G. (1976). The Economics of Caste and of the Rat Race and other Woeful Tales. The Quarterly Journal of Economics, 90(4), 599-617. https://doi.org/10.2307/1885324

Amodu, T. (2008). The Determinants of Compliance with Laws and Regulations with Special Reference to Health and Safety: A Literature Review. Report for the UK Health and Safety Executive, Research Report, 638.

Atlas, M. K. (2007). Enforcement Principles and Environmental Agencies: Principal-Agent Relationships in a Delegated Environmental Program. Law \& Society Review, 41(4), 939-980. https://doi.org/10.1111/j.1540-5893.2007.00330.x

Black, D. (1976). The behavior of law. New York: Academy Press.

Budzinski, O. (2014). The competition economics of financial fair play, Ilmenau Economics Discussion Papers, 85.

Dimitropoulos P., Leventis, S., \& Dedoulis, E. (2016). Managing the European football industry: UEFA's regulatory intervention and the impact on accounting quality. European Sport Management Quarterly, 16(4), 459-486. https://doi.org/10.1080/16184742.2016.1164213 
Dimitropoulos, P. E. (2011). Corporate governance and earnings management in the European football industry. European Sport Management Quarterly, 11(5), 495-523. https://doi.org/10.1080/16184742.2011.624108

El Kharbili, M. (2012). Business Process Regulatory Compliance Management Solution Frameworks: A Comparative Evaluation. Proceedings of the Eighth Asia-Pacific Conference on Conceptual Modeling (APCCM), Melbourne, Australia.

Fisse, B., \& Braithwaite, J. (1993). Corporations, Crime and Accountability. Cambridge: Cambridge University Press.

Franck, E. (2014). Financial Fair Play in European Club Football - What is it all about?, UZH Business Working Paper Series, 238.

Genn, H. (1993). Business responses to the regulation of health and safety in England. Law and Policy, 15(3), 219-234. https://doi.org/10.1111/j.1467-9930.1993.tb00104.x

Gunningham, N., \& Kagan, R. (2005). Regulation and Business Behavior. Law and Policy, 27(2), 213-218. https://doi.org/10.1111/j.1467-9930.2005.00197.x

Hutter, B. M., \& Jones, C. (2006). Business risk management practices: the influence of state regulatory agencies and non-state actors. CARR Discussion Paper, 41.

Iaria, M. (2012). How to spend $€ 2.5$ billion and be happy and dissatisfied. Available at: http://english.gazzetta.it/Football/15.10-2012/How-to-spend-e25-billion-and-be-happy-and-dissatisfied-912 915713957.shtml

Kagan, R. A. (1994). Regulatory Enforcement. In Rosenbloom, D. H. \& Schwartz, R.D. (Eds), Handbook of Regulation and Administrative Law. New York: Marcel Decker.

Kagan, R. A., \& Scholz, J. T. (1984). The Criminology of the Corporation and Regulatory Enforcement Strategies. In Hawkins, K \& Manning, P. (Eds), Enforcing Regulation. Boston: Kluwer-Nijhoff. https://doi.org/10.1007/978-94-017-5297-8_4

Kennedy, P. (2013). Left wing' supporter movements and the political economy of football. Soccer \& Society, 14(2), 277-290. https://doi.org/10.1080/14660970.2013.776462

Kesenne, S. (1996). League Management in Professional Team Sports with Win Maximizing Clubs. European Journal for Sports Management, 2, 14-22.

Maslow A. (1954), Motivation and personality, Harper's psychological series. New York: Harper.

Michie, J., \& Oughton, C. (2005). The corporate governance of professional football clubs in England. Corporate Governance: An International Review, 13, 517-531. https://doi.org/10.1111/j.1467-8683.2005.00446.x

Muller, J. C., Lammert, J., \& Hovemann, G. (2012). The Financial Fair Play Regulations of UEFA: An Adequate Concept to Ensure the Long-Term Viability and Sustainability of European Club Football? International Journal of Sport Finance, 7(2), 117-140.

Ogbonna, E., \& Harris, C. L. (2014). Organizational cultural perpetuation: A case study of an English Premier League football club. British Journal of Management, 25, 667-686. https://doi.org/10.1111/1467-8551.12037

Parker, C. (2002). The Open Corporation Effective Self-regulation and Democracy. Cambridge: Cambridge University Press. https://doi.org/10.1017/CBO9780511550034

Perskow, B. I. (2003). Sarbanes Oxley: Investment Company Compliance. The Journal of Investment Compliance, 3(4), 16-30. https://doi.org/10.1108/15285810210812871

Solberg, H. A., \& Haugen, K. K. (2010). European club football: Why enormous revenues are not enough? Sport in Society: Cultures, Commerce, Media, Politics, 13(2), 329-343.

Storm, R. K. (2012). The Need of Regulating Professional Soccer in Europe: A Soft Budget Constraint Argument. Sport, Business and Management: An International Journal, 2, 21-38. https://doi.org/10.1108/20426781211207647

Storm, R. K., \& Nielsen, K. (2012). Soft budget constraints in professional football. European Sport Management Quarterly, 12(2), 183-201. https://doi.org/10.1080/16184742.2012.670660

Titman, S., \& Wessels, R. (1988). The Determinants of Capital Structure Choice. The Journal of Finance, 43, 
1-19. https://doi.org/10.1111/j.1540-6261.1988.tb02585.x

UEFA. (2012). Uefa Club Licensing and Financial Fair Play Regulation.

UEFA. (2015). Uefa Club Licensing and Financial Fair Play Regulation.

UEFA. (2016). The European Club Footballing Landscape - Club Licensing Benchmarking Report.

Vopel, H. (2011). Do We Really Need Financial Fair Play in European Club Football? An Economic Analysis. CESifo DICE Report, 9(3), 54-60.

\section{Copyrights}

Copyright for this article is retained by the author(s), with first publication rights granted to the journal.

This is an open-access article distributed under the terms and conditions of the Creative Commons Attribution license (http://creativecommons.org/licenses/by/4.0/). 